\title{
Sexual signalling in female crested macaques and the evolution of primate fertility signals
}

\author{
James P Higham ${ }^{1,2^{*}}$, Michael Heistermann ${ }^{3}$, Carina Saggau ${ }^{1}$, Muhammad Agil ${ }^{4}$, Dyah Perwitasari-Farajallah ${ }^{5,6}$ and \\ Antje Engelhardt ${ }^{1,6,7}$
}

\begin{abstract}
Background: Female signals of fertility have evolved in diverse taxa. Among the most interesting study systems are those of multimale multifemale group-living primates, where females signal fertility to males through multiple signals, and in which there is substantial inter-specific variation in the composition and reliability of such signals. Among the macaques, some species display reliable behavioural and/or anogenital signals while others do not. One cause of this variation may be differences in male competitive regimes: some species show marked sexual dimorphism and reproductive skew, with males fighting for dominance, while others show low dimorphism and skew, with males queuing for dominance. As such, there is variation in the extent to which rank is a reliable proxy for male competitiveness, which may affect the extent to which it is in females' interest to signal ovulation reliably. However, data on ovulatory signals are absent from species at one end of the macaque continuum, where selection has led to high sexual dimorphism and male reproductive skew. Here we present data from 31 cycles of 19 wild female crested macaques, a highly sexually dimorphic species with strong mating skew. We collected measures of ovarian hormone data from faeces, sexual swelling size from digital images, and male and female behaviour.

Results: We show that both sexual swelling size and female proceptivity are graded-signals, but relatively reliable indicators of ovulation, with swelling size largest and female proceptive behaviours most frequent around ovulation. Sexual swelling size was also larger in conceptive cycles. Male mating behaviour was well timed to female ovulation, suggesting that males had accurate information about this.

Conclusion: Though probabilistic, crested macaque ovulatory signals are relatively reliable. We argue that in species where males fight over dominance, male dominance rank is surrogate for competitiveness. Under these circumstances it is in the interest of females to increase paternity concentration and assurance in dominants beyond levels seen in species where such competition is less marked. As such, we suggest that it may in part be variation in male competitive regimes that leads to the evolution of fertility signalling systems of different reliability.
\end{abstract}

Keywords: Fertility signals, Sexual selection, Sexual swellings, Primate

\section{Background}

The study of inter-sexual communication is central to sexual selection theory [1]. One of the most important aspects of condition that females can signal to males is fertility, and fertility signals have evolved widely throughout the animal kingdom from insects [e.g. paper

\footnotetext{
* Correspondence: jhigham@nyu.edu

'Jr Research Group on Sexual Selection, Reproductive Biology Unit, German

Primate Centre, Kellnerweg 4, Göttingen 37077, Germany

${ }^{2}$ Department of Anthropology, New York University, 25 Waverly Place, New

York, NY 10003, USA

Full list of author information is available at the end of the article
}

wasps, [2]] to birds [3], to mammals [e.g. pandas, [4]]. Among the most interesting study systems are those of primates living in multimale multifemale groups, where females signal fertility to males through multiple signals, and in which there is substantial inter-specific variation in the composition and reliability of such signals. Such signals include famous examples such as the anogenital (sexual) swellings of some female primates, the function of which continues to be the topic of much debate [e.g., [5-9]]. The general framework of the socio-ecological model postulates that females distribute themselves in space with respect to food resources, and that males

\section{Biomed Central}


then distribute themselves with respect to the distribution of males [10-12]. These factors therefore create the selective environment in which females evolve to indicate oestrus to males with increasing or decreasing accuracy, and the distribution of females in space and time consequently determines the general likelihood that females will exhibit sexual swellings [8]. One prevailing model for the evolution of these signals is the gradedsignal hypothesis, which proposes that swellings represent probabilistic signals of intra-cycle variation in fertility, with swellings being largest when this probability is highest, and smallest when it is lowest, such that ovulation occurs during the maximal swelling period [8]. This model proposes that such probabilistic signals exist in multi-male multi-female groups both to confuse and assure males of paternity. By biasing paternity towards good quality males, females may obtain a variety of indirect and direct benefits, while still enabling sufficient paternity confusion to prevent infanticide from other males who are unlikely (but not impossible) to be fathers.

Over the past decade, several studies of wild and freeranging primates have tested this evolutionary model, and collectively it has found broad support [e.g. chimpanzees, [13]; Barbary macaques, [14]; olive baboons, [15]; yellow baboons, [16]]. However, some studies have shown apparent inter-specific variability by finding that swellings do not reliably indicate ovulation [e.g. longtailed macaques, [17]; Assamese macaques, [18]]. At the same time a number of studies have focused on the extent to which female behaviour itself may indicate this timing to males. Both primate sexual swellings $[19,20]$ and female sexual behaviour [reviewed in [21], see also [22-24]] are known to be related to the ovarian hormones oestrogen (positively) and progesterone (negatively), such that both signal types may potentially indicate the timing of ovulation to males. Field studies over the last decade have, as in the case of sexual swellings, found inter-specific variability in relationships between ovulation and female sexual behaviour, with some studies finding that behaviour itself can be considered a probabilistic signal of ovulation [e.g. long-tailed macaques [17]; tonkean macaques, [23]] while other studies did not [e.g. Barbary macaques, [14]; olive baboons [24]].

The fitness benefits to females of employing probabilistic signals of ovulation are that they can offer both paternity confusion and assurance at the same time allowing high-ranking males who mate with females when conception is most likely a high degree of paternity assurance, while also offering a small probability of paternity to other males who mate when conception is possible but unlikely $[8,25]$. It has also been suggested that this mechanism might be further elaborated by the use of different signals in different modalities with different transmission differences $[24,26]$. As such, consorting males may receive extra assurance of their conceptive probability from signals to which other males do not have access $[24,26]$. Several studies have now shown that male sexual behaviour seems well timed to female ovulation in a probabilistic fashion [chimpanzees, [13,27]; long-tailed macaques, [26]; Barbary macaque, [28]; olive baboons, [24]]. The extent to which males may be influenced by swelling size and/or other cues in combination remains unclear however. In olive baboons, it has been shown that male consort behaviour is well correlated with female sexual swelling size, but that copulatory behaviour within consorts is not, suggesting that other cues may be important to consorting males [24].

One of the most interesting groups in which to study these inter-connected issues are the macaques, some of which show sexual swellings while others do not [8]. Interestingly, the macaques show a great deal of variation in levels of male reproductive skew [e.g. 6-25\% in M. sylvanus, [29-31]; 20-30 \% in M. mulatta, [32-34]; 60$90 \%$ in M. fascicularis, [35,36]], and in sexual dimorphism [37]. In species with high dimorphism and reproductive skew, males undergo contest competition for females, fighting for dominance, whereas in species with lower reproductive skew, males undergo scramble competition for females and queue for dominance [38]. The extent to which males compete in contests over dominance may determine the extent to which male rank is surrogate for some aspect of quality or competitive ability as opposed to merely representing group tenure length [34]. As such, high-ranking males may be desirable partners for females in some species, but less so in others. As more reliable signals of ovulation assist dominant males with the monopolization of female fertile periods, it may be in the evolutionary interest of females in species where males compete over dominance to give more reliable signals of ovulation, and females in species where males queue for dominance to give relatively less reliable signals of ovulation. As such, variation in macaque mating systems may be directly related to variation in fertility signalling systems, and greater male reproductive skew and sexual dimorphism should make it increasingly in the female's interest to offer relatively more reliable signals of ovulation.

Although studies of several macaque species have addressed issues of reproductive skew or the relative reliability of ovulatory signalling, the 7 species of Sulawesi macaque [39], which show the greatest levels of sexual dimorphism [37] (and consistent with this, in crested macaques, accompanying high levels of mating skew, Engelhardt et al. unpublished manuscript), remain poorly studied though see [20] for data on captive Tonkean macaques. Here, we present data on wild Sulawesi 
crested macaques at Tangkoko, a species of high sexual dimorphism [37], abundant signals of male dominance including bright colours and loud calls [40] and high male mating skew (Engelhardt et al. unpublished manuscript). Our analysis is structured around several explicit aims (Table 1): 1) to assess the extent to which changes in female sexual swelling size and behaviour are related to concentrations of the hormones oestrogen and progesterone; 2) to assess whether changes in female swelling size and behaviour are related to intra-cycle (the timing of ovulation) and inter-cycle (conceptive versus non-conceptive cycles) variation in conceptive probability, and so may potentially indicate this probability to others; 3) to assess whether changes in male behaviour are related to intra- and inter-variation in conceptive probability, and so determine whether males appear to have information about female fertility; 4) to assess the extent to which changes in male behaviour are related to sexual swelling size, and so whether males may respond to this cue in mating decisions. Due to high levels of sexual dimorphism and reproductive skew in this species we predicted that, although signals would be probabilistic in their nature [so still fulfilling paternity confusion roles, 8], female signals of ovulation may nonetheless be more reliable than those seen in related species. Consistent with this, we predicted that males would time their mating behaviour to ovulation relatively accurately.

\section{Methods}

\section{Study site and population}

The study was undertaken as part of the Macaca Nigra Project (founded March 2006) at the TangkokoBatuangus/Duasudara Nature Reserve at the northernmost tip of Sulawesi ( 1 o $34^{\prime} \mathrm{N}, 125$ o 14'E). The reserve was established in 1980, comprises an area of 8,867 hectares, with a sea boundary of $12 \mathrm{~km}$, and ranges from sea level to an elevation of $1,350 \mathrm{~m}[41,42]$. All research was undertaken between July 2006 and July 2007 on two study groups (Rambo I, Rambo II) which were studied previously by other researchers [43,44]. We rehabituated these groups from April 2006 to July 2006, and identified and named all group members according to individual characteristics such as size, gait, cuts,

Table 1 Summary of manuscript aims and how they are addressed by different sets of analyses

\begin{tabular}{llll}
\hline & \multicolumn{3}{l}{ Response Variables } \\
\hline Predictor Variables & $\begin{array}{l}\text { Swelling } \\
\text { Size }\end{array}$ & $\begin{array}{l}\text { Female } \\
\text { Behaviors }\end{array}$ & $\begin{array}{l}\text { Male } \\
\text { Behaviors }\end{array}$ \\
\hline E:P levels & Aim 1 & Aim 1 & \\
\hline $\begin{array}{l}\text { Day Relative to Ovulation; Cycle } \\
\text { Type (conceptive or non-conceptive) }\end{array}$ & Aim 2 & Aim 2 & Aim 3 \\
\hline Swelling size & & & \\
\hline
\end{tabular}

missing digits, scars etc. The home range of both groups overlapped and included primary forest, secondary forest and, for Rambo II, also gardens near the village. During the study period, both groups ranged in size from $65-70$ individuals, with Rambo I consisting of 10 adult males and 21 adult females, and Rambo II 7 adult males and 15 females. In total, data are presented here for 31 conceptive $(\mathrm{N}=16)$ and non-conceptive $(\mathrm{N}=15)$ cycles from 19 females covering 417 observation days and 2,443 hours of behavioural data.

\section{Faecal samples and hormone analysis}

We collected faecal samples for hormonal analysis opportunistically during follows of focal females, with collection occurring on a daily basis at least during midcycle, i.e. the period of maximum swelling and the seven following days to allow ovulation to be timed accurately in each cycle [45]. Overall, samples were collected 3-7 times per week in 31 cycles of 19 females. From these samples we were able to determine the timing of ovulation based on patterns of immunoreactive faecal progestogen concentrations measured by enzyme immunoassay (EIA). For this, samples were initially lyophilised and pulverized and an aliquot of the resulting powder was extracted with $80 \%$ methanol in water [46]. Fecal extracts were then analyzed for concentrations of immunoreactive $5 \alpha$-pregnane-3 $\alpha$-ol-20-one (i5-P-3OH), a group-specific measurement of $5 \alpha$-reduced 20 -oxo pregnanes, which represent abundant progesterone metabolites in faeces of a variety of mammals [for a review, see [47]], including macaques [48]. The assay has previously been applied successfully to monitor female reproductive status and to assess the timing of ovulation in other species of macaques $[48,49]$. Sensitivity of the assay at $90 \%$ binding was $20 \mathrm{pg} /$ well. Intra- and inter-assay coefficients of variation of high and low value quality controls were $7.8 \%$ and $15.4 \%$ (high) and $9.5 \%$ and $15.7 \%$ (low). The presumed time of ovulation was determined by counting back from the defined post-ovulatory rise in faecal progestogen levels [50]. In this way, a two day ovulation window was determined for all 31 cycles as the 2 and 3 days previous to the post-ovulatory rise in progestogens [as in, e.g., [17]]. To examine the relationship between our measures of female sexual swelling size and female behaviour, fecal extracts were also measured for concentrations of oestrogens using an EIA for the measurement of oestrone (E1C), an abundant oestrogen in macaque feces [51]. The assay was carried out as described elsewhere [52]. Sensitivity of the assay at $90 \%$ binding was $35 \mathrm{pg} /$ well. Intra- and inter-assay coefficients of variation of high and low value quality controls were $5.8 \%$ and $10.3 \%$ (high) and $6.9 \%$ and $13.9 \%$ (low). 


\section{Measuring swellings}

To investigate changes in swelling size, female sexual swellings were filmed with a digital video camera (Sony DCR-HC 90E) or were photographed with a digital camera (Canon EOS 350 D) on each observation day. Images were taken from directly behind the focal individual, under good light conditions. Five pictures of each female's perinea were taken to allow assessment of the size of the ischial callosities, in which we took a second image of a tape measure in the same location as the female with the camera in same position [following e.g., $[13,53]]$. The camera lens was kept on manual focus for the second image and the tape measure was moved until it was in focus, ensuring a high degree of accuracy in making sure that the tape measure and swelling were photographed at the same distance from the camera. Following this assessment, we used the size of the ischial callosities in all images to assess swelling size, [see [49]]. We measured the height of the left and right callosity in all five images using the measurement methods described below. We then took a mean of these five values.

During each cycle from each female we took an average 24 (range 5-63) swelling images. If the swelling was filmed with the video camera, sequences of the swelling were transferred to a Laptop with Video Capture 6.0 and Scenalyzer 3.52. One picture was captured daily from the video sequences of each observed female with ACDSee 5.0.1. If images were taken using the camera, the highest quality image (if multiple images were available) was chosen and images were transferred to Adobe Photoshop CS2. To correct for differences in camera distance and zoom between images, we adjusted each swelling size measurement for the known size of the ischial callosities (see above). Wherever possible, this was done using the left ischial callosity; if the left ischial callosity was not clearly observable for any reason, the right one was used instead. We measured the ischial callosity height in each image using the Adobe Photoshop measurement tool, and expressed this as a fraction of the known ischial callosity height. We then measured the swelling height, and multiplied this by the ischial collosity fraction to get the true swelling size measurement. We undertook two different measurements of swelling size in this way (Figure 1): swelling width (a horizontal line under the edges of the left and right ischial callosity); and swelling height (a line from the highest point of the swelling down to the line under the ischial callosities).

\section{Measuring Behaviour}

Behavioural data were collected on adult females exhibiting swellings with several Psion Workabout Pro M handhelds (Software: PTab Spreadsheet v.3.0; Z4Soft). Data were collected using instantaneous focal animal sampling [54]. Focal females were followed every day from dawn until dusk, with observation time averaging $5.9 \pm 0.1$ hours per observation day. We focused our observations and analyses on a number of key sociosexual behaviours (Table 2).

\section{Data analysis}

As female hormone levels may be related to female behaviour and as, independently of this, female behaviour may indicate the timing of ovulation specifically, we assessed relationships between sexual swelling size and behaviour and both hormone levels, and estimates of the timing of ovulation based on progestogen levels, separately. To do this, we first took the progestogen $(\mathrm{P})$ and estrogen (E) levels measured from our faecal samples and tested whether female sexual behaviour was related

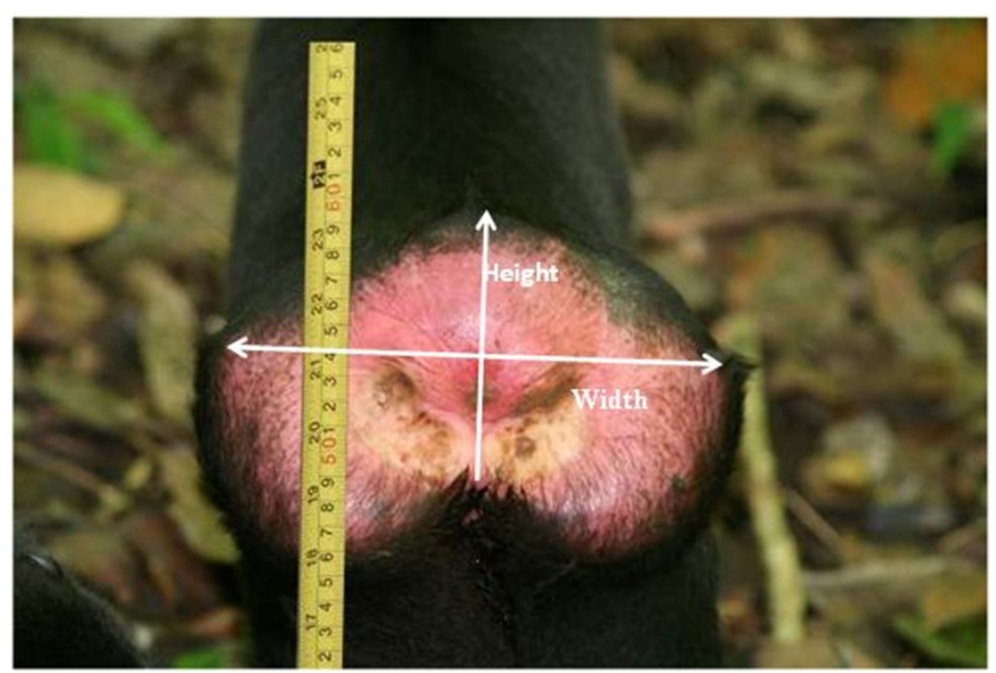

Figure 1 Measurements of swelling size taken in each image. 
to the E:P ratio [e.g. [26]]. When aligning measured E:P to sexual behaviour we had to consider both that there is an excretion delay before hormone levels measured in faeces reflect those measured in blood [e.g. [55]], but also that there may be a delay in response of swelling size and behaviour to changes in blood hormone levels [e.g. [19]]. As such, we aligned hormone levels measured from faeces to measures of swelling size and sexual behaviour all collected on the same day. A previous study that systematically tested different potential alignments found that such an alignment produced significant results between hormone levels and sexual behaviour in female baboons [23].

We tested relationships between the timing of ovulation and swelling size and behaviour using the 14 day period around ovulation only. We created a scale (Day Relative to Ovulation $=$ DayRO) whereby the two days of the ovulation window were both considered Day 0, and each day before (e.g. Day -1, Day -2) and after this (e.g. Day +1 , Day +2 ) were designated accordingly. We did this and analysed data for a period representing the total fertile phase of the cycle [the ovulation window plus the two preceding days to allow for sperm longevity, see e.g. [14]] and a 10 day period surrounding the fertile phase ( 5 days before, 5 days after). As we do not expect a linear relationship between this scale and measures of swelling size and behaviour, but instead peak around Day 0 with lower values on either side, we squared this scale for analysis [as in $[15,24,56,57]]$. We classified cycles as conceptive $(\mathrm{N}=16)$ if an infant was born around 6 months later [see [58]], or if it was the last female cycle [either assessed hormonally or by the occurrence of swellings, as $M$. nigra does not exhibit postconception swellings, see [58]; Engelhardt et al. unpublished manuscript], or if miscarriage was subsequently observed (assessed by female bleeding from the vagina, $\mathrm{N}=3)$. Cycles were classified as non-conceptive $(\mathrm{N}=15)$ if they were immediately followed by another cycle (assessed hormonally or by the occurrence of swellings, as above).

To assess relationships between swelling height and width, and between hormone levels and swelling size (Aim 1), we used general Linear Mixed Models (LMMs) to assess the response of swelling height to variation in a fixed covariate (swelling width or E:P) while controlling for multiple observations of the same females from the same groups (random factors, female ID nested within group). As many of the behavioural variables were not normally distributed but featured a binary response (e.g. either the female gave a copulation call or she did not), Generalized Linear Mixed Models (GLMMs) were used with a binomial error structure and a logit link function. For models of male mating and mounting, rates $(\mathrm{n} / \mathrm{hr})$ were normally distributed after $\log$ transformation and general LMMs were undertaken. For models of female parading and solicitation rates, values were not normally distributed even after transformation. As such, these variables were treated as counts and modelled using poisson error structures, in which counts were offset for observation time.

In models of female and male behaviour and variation in intra- and inter-cycle fertility (Aims 2 and 3), all

Table 2 Tested behaviours, quantification method and results of analyses

\begin{tabular}{|c|c|c|c|c|c|c|c|}
\hline Sex & Behaviour & Quantification & Pre-Fertile & Fertile & Post-Fertile & $P$ value & $\begin{array}{l}\text { Relationship } \\
\text { to OV }\end{array}$ \\
\hline \multirow[t]{6}{*}{ Female } & Approach and solicitation & $\begin{array}{l}\text { Count offset for observation } \\
\text { time (i.e. rate). }\end{array}$ & 3.11 & 3.67 & 1.94 & $<0.001$ & + \\
\hline & $\begin{array}{l}\text { Approach and parade (ritualized series of } \\
\text { presentations involving passing back and } \\
\text { forth in front of the male) }\end{array}$ & $\begin{array}{l}\text { Count offset for observation } \\
\text { time (i.e. rate). }\end{array}$ & 0.68 & 0.79 & 0.43 & $<0.001$ & + \\
\hline & Lipsmack at male during copulation & Binary (female does or does not). & 0.57 & 0.64 & 0.51 & $=0.003$ & + \\
\hline & Look at male during copulation & Binary (female does or does not) & 0.91 & 0.91 & 0.88 & $p>0.1$ & None \\
\hline & Reach back to male during copulation & Binary (female does or does not) & 0.38 & 0.44 & 0.36 & $<0.001$ & + \\
\hline & Give copulation call during copulation & Binary (female does or does not) & 0.22 & 0.29 & 0.14 & $<0.001$ & + \\
\hline \multirow[t]{5}{*}{ Male } & Ignore female approach & Binary (male does or does not) & 0.49 & 0.47 & 0.41 & $p=0.009$ & - \\
\hline & Inspect female & Binary (male does or does not) & 0.45 & 0.48 & 0.50 & $p>0.1$ & None \\
\hline & Mount female & Logged rate (n/hr) & 2.68 & 3.56 & 2.28 & $P<0.001$ & + \\
\hline & Mate with female & Logged rate $(\mathrm{n} / \mathrm{hr})$ & 2.71 & 3.52 & 2.27 & $P<0.001$ & + \\
\hline & Give copulation call during copulation & Binary (male does or does not) & 0.41 & 0.57 & 0.53 & $P<0.001$ & + \\
\hline
\end{tabular}

Mean values across all cycles are given for the 5 days before the fertile period (Pre-Fertile), the four day fertile period (Fertile) and the five days following the fertile period (Post-fertile). Values were first averaged across all cycles for each day with respect to the ovulation window, then across all days within each respective period. For rate behaviours, values given here are $n / h r$. For binary variables, values given are proportion of copulations in which the behaviour occurred. $\mathrm{P}$ values of the statistical test employed are given (see text for full statistical results). 
models featured a different behavioural variable as the response, DayRO (covariate) and Cycle Type as fixed variables, and female ID nested within group as random factors. For models testing relationships between male behaviour and sexual swelling size (Aim 4), the same model structures were used but with swelling height (covariate) replacing DayRO and Cycle Type as the fixed variable. Statistics were performed in PASW 18.0 (LMMs) and R 2.13.0 (GLMMs). Models of binary response variables were undertaken using the lmer function of the lme4 package [59], while female parading and solicitation rate models were undertaken using the MCMCglmm package [60], as data were overdispersed. All tests were two-tailed and $p<0.05$ was considered statistically significant.

\section{Results}

Our hormonal data indicated clear oestrus cycles in the study females, with clear oestrogen peaks occurring 3 days before the post-ovulatory rise in progestogen levels (Figure 2).

1) Relationship between female hormones and sexual swelling size and female behaviour.

Variation in sexual swelling height and width was highly significantly related $\left(\mathrm{F}_{1,302.0}=197.6, p<0.001\right.$; Figure $3 \mathrm{a})$. For this reason, we used swelling height only in all further analyses. The E:P ratio significantly predicted sexual swelling height, with increasing E:P related to increased swelling size $\left(\mathrm{F}_{1,271.3}=6.546, p=0.011\right)$. The E:P ratio also predicted some female behaviours, with females more likely to look back $(\mathrm{z}=4.472, p<0.001)$ and lipsmack $(\mathrm{z}=8.806, p<0.001)$ during mating when the E:P ratio was higher. Females also solicited $(\beta=$ 0.0005192 , Lower $\mathrm{CI}=0.0001659$, Upper $\mathrm{CI}=$ $0.0009039, p=0.004)$ and presented $(\beta=0.0007584$, Lower $\mathrm{CI}=0.0002467$, Upper

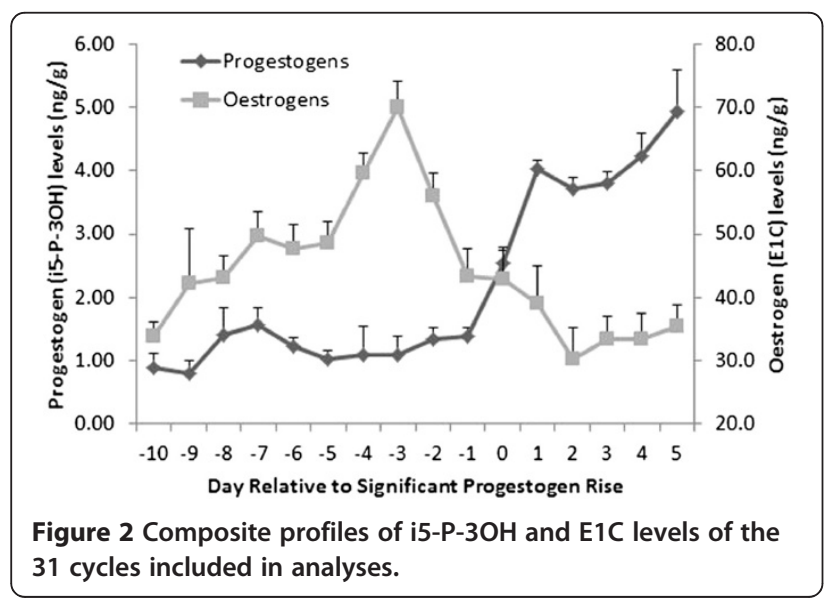

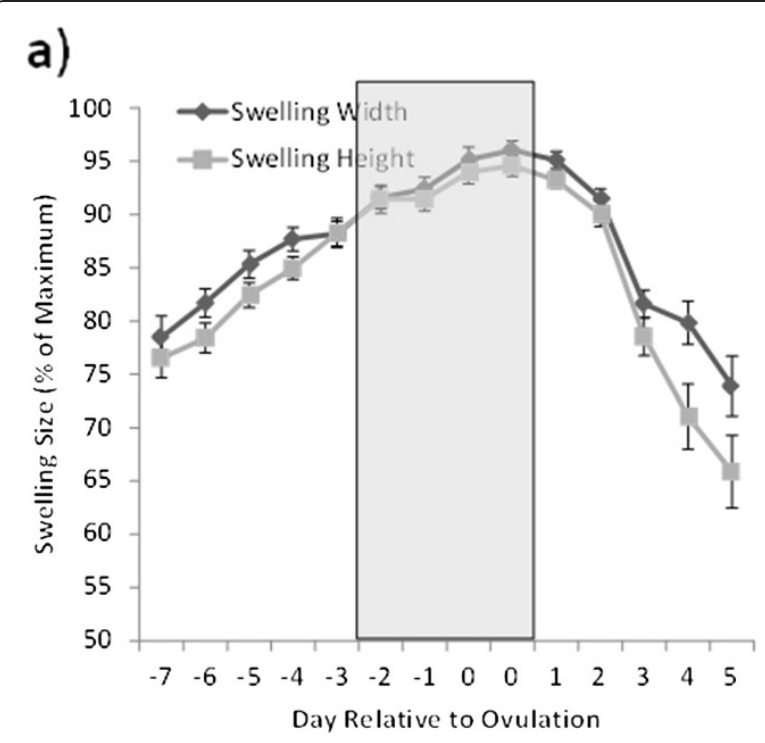

b)

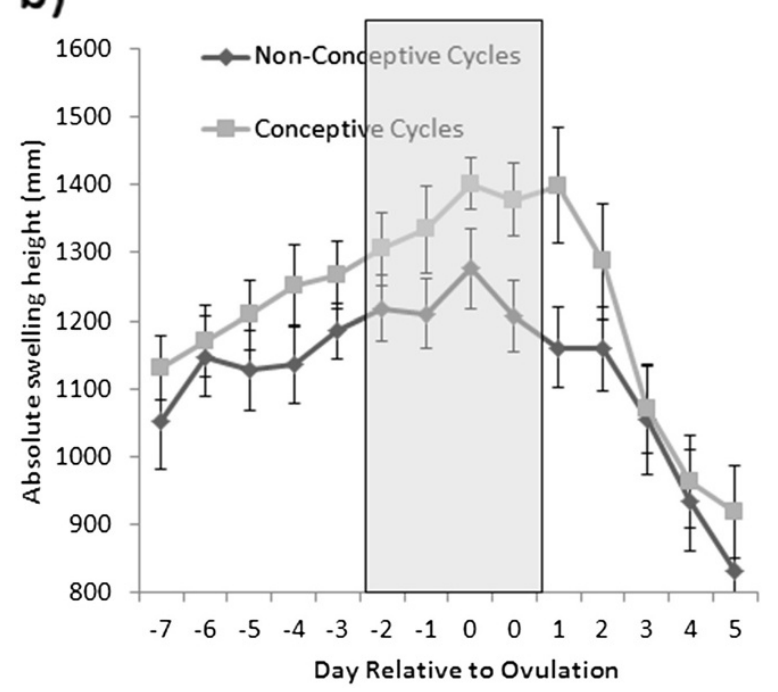

Figure 3 Swelling size in relation to the timing of ovulation: a) the close agreement between measures of swelling height and width; b) the difference in swelling height between conceptive and non-conceptive cycles. The grey shaded area represents a presumed four day fertile period that incorporates the two-day ovulation window.

$\mathrm{CI}=0.0012233, p=0.002)$ at higher rates when E:P levels were higher. No other analysed behaviours were significantly related to the E:P ratio.

2) Relationship between intra- and inter-cycle variation in fertility and sexual swelling size and female behaviour.

Sexual swelling height was significantly related to DayRO $\left(\mathrm{F}_{1,289.4}=63.685, p<0.001\right.$, Figure 3a). There was also a significant effect of cycle type, with conception cycles having higher swelling heights (i.e. bigger swellings) for each day with respect to 
ovulation $\left(\mathrm{F}_{1,305.9}=10.877, p=0.001\right.$; Figure $\left.3 \mathrm{~b}\right)$. Most of the analysed behavioural patterns were significantly related to the timing of ovulation (Table 2). Females solicited $(\beta=-0.010326$, Lower $\mathrm{CI}=-0.016677$, Upper $\mathrm{CI}=-0.004106, p<0.001)$, and paraded $(\beta=-0.016278$, Lower $\mathrm{CI}=-0.025348$, Upper $\mathrm{CI}=-0.006279, p<0.001)$ towards males at higher rates closer to ovulation. During mating, females lipsmacked at males $(\mathrm{z}=-2.966, p=0.003)$, reached back to males $(\mathrm{z}=-6.125, p<0.001)$ and gave copulation calls $(\mathrm{z}=-7.205, p<0.001)$ significantly more often closer to ovulation. Three female behavioural patterns showed a statistically significant difference between conception and non-conception cycles. Females lipsmacked $(\mathrm{z}=-3.655, p<0.001)$, gave copulation calls $(\mathrm{z}=-2.662, p=0.008)$ and looked back significantly more often in non-conception cycles than in conception cycles $(\mathrm{z}=-2.225, p=0.026)$. However, mean (across all cycles) differences in these three behavioural variables between the two cycle types were less than $10 \%$.

3) Relationship between male behaviour and intra- and inter-cycle variation in fertility.

Several analysed male behavioural patterns showed a significant correlation to the timing of ovulation (Table 2). Crucially, males mounted $\left(t_{1,321}=-5.077\right.$, $p<0.001)$ and mated $\left(t_{1,322}=-5.050, p<0.001\right)$ with females more often closer to ovulation. Males also ignored female approaches significantly less often closer to ovulation $(\mathrm{z}=2.587, p=0.009)$ and were more likely to give a copulation call during mating $(\mathrm{z}=-9.106, p<0.001)$ when ovulation was approaching. Two male behavioural patterns showed a significant difference between conception and nonconception cycles. Males ignored female solicitations significantly less often in conceptive cycles $(\mathrm{z}=-2$ $.814, p=0.004)$, and gave copulation calls significantly less often in conceptive cycles $(\mathrm{z}=-7.915, p<0.001)$. However, mean (across all cycles) differences in these three behavioural variables between the two cycle types were less than $10 \%$.

4) Relationship between male behaviour and sexual swelling size.

The key male behaviours of mounting and mating rates were both significantly positively related to sexual swelling height (mounting, $\mathrm{t}_{1,265}=3.552$, $p<0.001$; mating, $\mathrm{t}_{1,265}=3.577 p<0.001$ ).

Interestingly, both of these effects were independent of variation in intra-cycle fertility. As such, in models containing both DayRO and swelling height, both variables emerge as independently significant factors influencing male mounting (swelling height, $\mathrm{t}_{2,264}=2.531, \mathrm{p}=0.012$; DayRO, $\mathrm{t}_{2,264}=-2.098$, $p=0.037$ ) and mating (swelling height, $\mathrm{t}_{2,264}=2.537$, $p=0.012$; DayRO, $\mathrm{t}_{2,264}=-2.171, p=0.031$ ) rates. No other behaviours were significant related to swelling height (all $p>0.1$ ).

\section{Discussion}

Our results show that crested macaque females give signals of ovulation that are probabilistic in nature, but that are relatively clear compared to those shown by other multi-male multi-female group-living catarrhines. Unlike in many previous studies of other primate species, where sexual swellings but not behaviour indicated the timing of ovulation [e.g. Barbary macaques, 14; olive baboons, $[15,24]]$, or where behaviour but not sexual swellings indicated ovulation [e.g. long-tailed macaques, [17]], measures of both sexual swelling size and sexual behaviour indicated intra-cycle variation in fertility, potentially indicating the timing of ovulation to males. The only other species yet studied which may show this is the very closely related Tonkean macaque [23], although fine-scale analyses have not yet been undertaken. Significant behavioural measures include the frequency of copulation calls. To our knowledge this is the first time that measures of copulation calls have been shown to vary specifically with respect to ovulation, adding a further modality to the range of signals to which crested macaques may indicate ovulatory timing. Consistent with the idea that males received reliable information about female reproductive status, numerous key male sexual behaviours were well timed to the most fertile part of the cycle. These data add to those of several other catarrhine species that suggest that males may be able to time mating effort to female ovulation [e.g. longtailed macaques, [26]; chimpanzees, [13,27]; Barbary macaques, [28]; olive baboons, [24]]. Despite this however, crested macaque females are nonetheless still probabilistic signallers, with swellings expressed over multiple days that extend beyond the fertile phase. As such, their swellings are still consistent with the gradedsignal framework [8].

Our analyses of variation in inter-cycle fertility revealed significant differences between conceptive and non-conceptive cycles. Females expressed significantly larger sexual swellings in conceptive cycles than in nonconceptive cycles, and also exhibited some behaviours less often in conception cycles (though behavioural differences were for only a few variables, and were less than $10 \%$ different between cycle types). Males showed some behavioural differences between cycle types, but consistent with results in some other species [e.g. chimpanzees [13]], males did not show differences in mating rates between conceptive and non-conceptive cycles. Other analyses from our dataset focusing on mating skew show that alpha males specifically may respond to conceptive 
cycles to a greater extent than non-conceptive cycles in more functionally important behaviours (Engelhardt et al. unpublished manuscript). Given the strong mating skew and limited reproductive opportunities for lower ranked males seen in this species (Engelhardt et al. unpublished manuscript), males may not mate at higher rates in conceptive than non-conceptive cycles because for most males, all opportunities for mating must be taken. Another possibility is that alpha males, who dominate consortships during fertile phases (Engelhardt et al. unpublished manuscript), have increased information about female cycle status not available to all males. Similarly, only group resident male chacma baboons consorted more with females during conceptive cycles [61] consistent with a potential role for close access $[24,26]$ and familiarity [62] for males in interpreting female primate fertility signals.

The apparent relative reliability of female ovulatory signalling is consistent with the low female oestrus synchrony, high mating skew (Engelhardt et al. unpublished manuscript) and high sexual dimorphism [47] found in this species, as well as the large canines, bright colours and loud calls that have evolved in males [40]. Such evidence indicates both that males are able to exert a high degree of control over female reproduction, and that males engage in contest competition for females, and fight for dominance. Under such circumstances, male dominance rank may be reliably related to male competitive ability [unlike in say, rhesus macaques, where it may be primarily related to group tenure length; [63]], such that high ranking males may be the preferred partners of females. As clearer signals of ovulation further enable male monopolization of female fertile periods by dominant males, it may only be in the evolutionary interest of females to give clearer signals under such circumstances. Females are more likely to derive indirect benefits such as "good genes" [64] from high ranking males in these types of competitive male-male environments. Intra-group direct benefits such as food tolerance [64] should be available from high ranking males in all regimes, but other direct benefits such as predator protection should be more available from high-ranking males where rank is achieved through male strength rather than through queuing.

Our analysis of relationships between male behaviour and sexual swelling size indicate that male behaviour was well timed to this reliable signal of the timing of ovulation. Interestingly male behaviours such as inspection were not related to the timing of ovulation [similar to long-tailed macaques, [17]]. The prevailing evolutionary model for sexual swelling function is one in which females offer unreliable and only probabilistic signals of ovulation which allows females to offer some paternity probability to numerous males, while nonetheless offering the most assurance to the dominant male [8]. It has also been suggested that females may further elaborate this mechanism by using multimodal signals with different active spaces, in which females can simultaneously offer different males different information about ovarian function [24,26]. Under such a theoretical system, females may offer less reliable signals such as sexual swellings to all males, while making more reliable signals of ovulation such as olfactory signals only available to males with close access to the female $[24,26]$. Interestingly, this concept seems not to hold for our study species. As we have argued above, the reason for this may be that in species with low oestrus synchrony, high mating skew, monopolized mating and contest competition for dominance, there may be increased advantages to females of signalling ovulation relatively more reliably, and of placing an increased emphasis on biasing paternity towards the dominant. As such, our data provide further evidence that the functional role of sexual swellings is unlikely to prove ubiquitous across all species.

\section{Conclusion}

Our data provide new insights into the evolution of female fertility signals in a taxa in which there is a high degree of variation in the reliability of such signals. Unlike in many multimale multifemale group-living primate species where signals of ovulation appear relatively unreliable, females in this very sexually dimorphic macaque species signal differences in intra- and inter-cycle conceptive probabilities using different types of signal, in this case sexual swellings and female behaviour. Male crested macaques appear to have information about the timing of female ovulation, and time their mating effort appropriately. Together with data on mating skew and the monopolisation of females by dominant males (Engelhardt et al. unpublished manuscript), the present data help build a picture of a highly interesting species in which dominant males fight for rank, monopolize mating and reproduction, and in which females signal fertility to males in a probabilistic but relatively (compared to related species) reliable fashion. Collectively, our data are important for understanding the evolution of female fertility signals because they represent an extreme end of the variation seen across the macaques, some of which do not possess clear signals of ovulation such as sexual swellings at all. Our suggestion that comparative variation in male competitive regimes may be linked to the evolution of fertility signalling systems of different reliability provides testable predictions for other species. Further understanding the selective pressures that have given rise to such comparative variation will provide a wealth of insight into the veracity of current 
socio-ecological models, as well as our understanding of signal evolution.

\section{Competing interests}

The authors declare that they have no competing interests.

\section{Author contributions}

$\mathrm{JH}$ processed data, undertook analyses, drew the figures and wrote the paper; $\mathrm{MH}$ provided reagents, oversaw the hormonal analyses and helped draft the manuscript; CS processed data and undertook analyses; MA Coconceived the project, oversaw processing of hormone samples and provided logistical and institutional support in Indonesia; DP-F co-conceived the project and provided logistical and institutional support in Indonesia; AE conceived the project, collected and processed data and co-wrote the paper. All authors read and approved the final manuscript.

\section{Acknowledgements}

We thank all team members of the Macaca Nigra Project at Tangkoko for supporting data collection. We also acknowledge Elise Huchard for helpful discussion on statistics, Constance Dubuc for general discussion, Andrea Heistermann for carrying out all hormone analyses and Jan-Boje Pfeifer for logistical support in the field. Furthermore, A.E. thanks Dr Joko Pamungkas from the Primate Research Centre for supporting her stay in Indonesia. This research was funded by the German Research Council together with the Federal Ministry for Economic Cooperation and Development (EN719/1) and the German Academic Exchange Service (DAAD). We gratefully acknowledge the permission of the Indonesian Institute of Sciences (LIPI), the Directorate General of Forest Protection and Nature Conservation (PHKA) and the Department for the Conservation of Natural Resources (BKSDA), North Sulawesi, particularly Pak Domingus and Pak Yunus, to conduct research in the Tangkoko-Batuangus/Duasudara Nature Reserve. All research described was based on non-invasive samples and conformed to the ABS/ASAB guidelines for the ethical treatment of animals. All work abided by all laws of both Indonesia and Germany.

\section{Author details}

'Jr Research Group on Sexual Selection, Reproductive Biology Unit, German Primate Centre, Kellnerweg 4, Göttingen 37077, Germany. ${ }^{2}$ Department of Anthropology, New York University, 25 Waverly Place, New York, NY 10003, USA. ${ }^{3}$ Reproductive Biology Unit, German Primate Centre, Kellnerweg 4, Göttingen 37077, Germany. ${ }^{4}$ Faculty of Veterinary Medicine, Bogor Agricultural University, Bogor, Indonesia. ${ }^{5}$ Primate Research Center, Bogor Agricultural University, Bogor, Indonesia. ${ }^{6}$ Faculty of Mathematics \& Natural Sciences, Bogor Agricultural University, Bogor, Indonesia. ${ }^{7}$ Courant Research Centre "Evolution of Social Behaviour", Kellnerweg 6, Göttingen 37077, Germany.

Received: 7 November 2011 Accepted: 18 June 2012 Published: 18 June 2012

\section{References}

1. Darwin C: The descent of man and selection in relation to sex. London: J. Murray; 1871

2. Tannure-Nascimento IC, Nascimento FS, Zucchi R: The look of royalty: visual and odour signals of reproductive status in a paper wasp. Proc Roy SOC B 2008, 275:2555-2561.

3. Montgomerie R, Thornhill R: Fertility advertisement in birds: a means of inciting male-male competition? Ethology 1989, 81:209-220.

4. Charlton BD, Keating JL, Li RG, Yan H, Swaisgood RR: Female giant panda (Ailuropoda melanoleuca) chirps advertise the caller's fertile phase. Proc Roy Soc B 2010, 277:1101-1106.

5. Clutton-Brock TH, Harvey PH: Evolutionary rules and primate societies. In Growing points in ethology. Edited by Bateson PPG, Hinde RA. Cambridge: Cambridge University Press; 1976:195-237.

6. Hamilton WJI: Significance of paternal investment by primates to the evolution of adult male-female associations. In Primate paternalism. Edited by Taub DM. New York: van Nostrand Reinhold; 1984:303-335.

7. Hrdy S: The women that never evolved. 2nd edition. Cambridge, MA: Harvard University Press; 1981.
8. Nunn C: The evolution of exaggerated sexual swellings in primates and the graded signal hypothesis. Anim Behav 1999, 58:229-246.

9. Pagel M: The evolution of conspicuous oestrus advertisement in Old World monkeys. Anim Behav 1994, 27:1-36.

10. Wrangham RW: An ecological model of female-bonded primate groups. Behaviour 1980, 75:262-300.

11. van Schaik CP: The ecology of social relationships amongst female primates. In Comparative socioecology: The behavioural ecology of humans and other mammals. Edited by Standen V, Foley RA. London: Blackwell Scientific Publications; 1989:195-218.

12. Sterck EHM, Watts DP, van Schaik CP: The evolution of female social relationships in nonhuman primates. Behav Ecol Sociobiol 1997, 41:291-309.

13. Deschner T, Heistermann M, Hodges K, Boesch C: Female sexual swelling size, timing of ovulation and male behavior in wild West African chimpanzees. Horm Behav 2004, 46:204-215.

14. Brauch K, Pfefferle D, Hodges K, Möhle U, Fischer J, Heistermann M: Female sexual behavior and sexual swelling size as potential cues for males to discern the female fertile phase in free-ranging Barbary macaques (Macaca sylvanus) of Gibraltar. Horm Behav 2007, 52:375-383.

15. Higham JP, MacLarnon AM, Ross C, Heistermann M, Semple S: Baboon sexual swellings: Information content of size and color. Horm Behav 2008, 53:452-462.

16. Gesquiere LR, Wango EO, Alberts SC, Altmann J: Mechanisms of sexual selection: sexual swellings and estrogen concentrations as fertility indicators and cues for male consort decisions in wild baboons. Horm Behav 2007, 51:114-125.

17. Engelhardt A, Hodges JK, Niemitz C, Heistermann M: Female sexual behaviour, but not sex skin swelling, reliably indicates the timing of the fertile phase in wild long-tailed macaques (Macaca fasicularis). Horm Behav 2005, 47:195-204.

18. Fürtbauer I, Heistermann M, Schülke O, Ostner J: Concealed fertility and extended female sexuality in a non-human primate (Macaca assamensis). PLoS One 2011, 6:e23105.

19. Zuckerman S, Parkes AS: Observations on the secondary sexual charactersistics in monkeys. J Endocrinol 1939, 1:430-439.

20. Gillman J: The effect of multiple injections of progesterone on the turgescent perineum of the baboon (Papio porcarius). Endocrinology 1940, 26:1072-1077.

21. Michael RP, Zumpe D: A review of hormonal factors influencing the sexual and aggressive behavior of macaques. Am J Primatol 1993, 30:213-241.

22. Zehr JL, Maestripieri D, Wallen K: Estradiol increases female sexual initiation independent of male responsiveness in rhesus monkeys. Horm Behav 1998, 33:95-103.

23. Aujard F, Heistermann M, Thierry B, Hodges JK: The functional significance of behavioral, morphological, and endocrine correlates across the ovarian cycle in semifree ranging female Tonkean macaques. Am J Primatol 1998, 46:285-309.

24. Higham JP, Semple S, MacLarnon A, Heistermann M, Ross C: Female reproductive signaling, and male mating behavior, in the olive baboon. Horm Behav 2009, 55:60-67.

25. Bercovitch BF: Female co-operation, consortship maintenance, and male mating success in savanna baboons. Anim Behav 1995, 50:137-149.

26. Engelhardt A, Pfeifer J-B, Heistermann M, Niemitz C, van Hooff JARAM, Hodges JK: Assessment of female reproductive status by male longtailed macaques, Macaca fasicularus, under natural conditions. Anim Behav 2004, 67:915-924.

27. Emery Thompson M, Wrangham RW: Male mating interest varies with female fecundity in Pan troglodytes schweinfurthii of Kanyawara, Kibale National Park. Int J Primatol 2008, 29:885-905.

28. Heistermann M, Brauch K, Möhle U, Pfefferle D, Dittami J, Hodges K: Female ovarian cycle phase affects the timing of male sexual activity in freeranging Barbary macaques (Macaca sylvanus) of Gibraltar. Am J Primatol 2008, 70:44-53.

29. Paul A, Kuester J, Timme A, Arnemann J: The association between rank, mating effort, and reproductive success in male Barbary macaques (Macaca sylvanus). Primates 1993, 34:491-502.

30. Kuemmerli R, Martin RD: Male and female reproductive success in Barbary macaques (Macaca sylvanus) in Gibraltar: No evidence for rank dependence. Int J Primatol 2005, 26:1229-1249. 
31. Brauch K, Hodges JK, Engelhardt A, Fuhrmann K, Shaw E, Heistermann M: Sex-specific reproductive behaviours and paternity in free-ranging Barbary macaques (Macaca sylvanus). Behav Ecol Sociolbiol 2008, 62:1453-66.

32. Berard JD, Nürnberg P, Epplen JT, Schmidtke J: Alternative reproductive tactics and reproductive success in male rhesus macaques. Behaviour 1994, 129:177-201.

33. Widdig A, Bercovitch FB, Streich WJ, Nürnberg P, Krawczak M: A longitudinal analysis of reproductive skew in male rhesus macaques. Proc Roy Soc B 2004, 271:819-826.

34. Dubuc C, Muniz L, Heistermann M, Engelhardt A, Widdig A: Testing the Priority-of Access model in a seasonally breeding primate species (Macaca mulatta). Behav Ecol Sociobiol 2011, 65:1615-1627.

35. de Ruiter JR, Van Hooff JARAM, Scheffrahn W: Social and genetic aspects of paternity in wild long-tailed macaques (Macaca fascicularis). Behaviour 1994, 129:203-224.

36. Engelhardt $A$, Heistermann $M$, Hodges JK, Nürnberg $P$, Niemitz C: Determinants of male reproductive success in wild long-tailed macaques (Macaca fascicularis) - male monopolisation, female mate choice or post-copulatory mechanisms? Behav Ecol Sociobiol 2006, 59:740-52.

37. Plavcan JM: Sexual dimorphism in primate evolution. Am J Phys Anthropol 2001, 116:25-53.

38. van Noordwijk MA, van Schaik CP: Sexual selection and the careers of primate males: paternity concentration, dominance-acquisition tactics and transfer decisions. In Sexual selection in primates. Edited by Kappeler P, van Schaik CP. Cambridge: Cambridge University Press; 2004:208-229.

39. Riley EP: The endemic seven: Four decades of research on the Sulawesi macaques. Evol Anthropol 2010, 19:22-36.

40. Neumann C, Assahad G, Hammerschmidt K, Perwitasari-Farajallah D, Engelhardt A: Loud calls in male crested macaques, Macaca nigra: a signal of dominance in a tolerant species. Anim Behav 2010, 79:187-193.

41. Collins NM, Sayer JA, Whitmore TC: The conservation Atlas of tropical forests: Asia and the Pacific. New York: Simon \& Schuster; 1991.

42. Rosenbaum B, O'Brien TG, Kinnaird M, Supriatna J: Population densities of sulawesi crested black macaques (Macaca nigra) on Bacan and Sulawesi, Indonesia: effects of habitat disturbance and hunting. Am J Primatol 1998, 44:89-106.

43. O'Brien TG, Kinnaird MF: Behavior, diet, and movements of the sulawesi crested black macaque (Macaca nigra). Int J Primatol 1997, 18:321-351.

44. Kinnaird MF, O'Brien TG: A contextual analysis of the loud call of the Sulawesi crested black macaque, Macaca nigra. Tropic Biodiv 1999 6:37-42.

45. Hodges JK, Heistermann M: Field Endocrinology: monitoring hormonal changes in free-ranging primates. In Field and Laboratory methods in primatology $\left(2^{\text {nd }} E d\right)$. Edited by Setchell J, Curtis D. Cambridge: Cambridge University Press; 2011:282-294.

46. Heistermann M, Finke M, Hodges JK: Assessment of female reproductive status in captive-housed Hanuman langurs (Presbytis entellus) by measurement of urinary and fecal steroid excretion patterns. Am J Primatol 1995, 37:275-284.

47. Schwarzenberger E, Möstl E, Palme R, Bamberg E: Faecal steroid analysis for noninvasive monitoring of reproductive status in farm, wild and zoo animals. Anim Reprod Sci 1996, 42:515-526.

48. Heistermann M, Uhrigshardt J, Husung A, Kaumanns A, Hodges JK: Measurement of faecal steroid metabolites in the lion-tailed macaque (Macaca silenus): A non-invasive tool for assessing female ovarian function. Primate Report 2001, 59:27-42.

49. Möhle U, Heistermann M, Dittami J, Reinberg V, Hodges JK: Patterns of anogenital swelling size and their endocrine correlates during ovulatory cycles and early pregnancy in free-ranging Barbary macaques (Macaca sylvanus) of Gibraltar. Am J Primatol 2005, 66:351-368.

50. Heistermann M, Ziegler $T$, van Schaik CP, Launhardt K, Winkler P, Hodges JK: Loss of oestrus, concealed ovulation and paternity confusion in freeranging Hanuman langurs. Proc Roy Soc B 2001, 268:2445-2451.

51. O'Neill AC, Fedigan LM, Ziegler TE: Relationship between ovarian cycle phase and sexual behavior in female Japanese macaques (Macaca fuscata). Am J Phys Anthropol 2004, 125:352-362.

52. Heistermann M, Hodges JK: Endocrine monitoring of the ovarian cycle and pregnancy in the saddle-back tamarin (Saguinus fuscicollis) by measurement of steroid conjugates in urine. Am J Primatol 1995, 35:117-127.
53. Domb LG, Pagel M: Sexual swellings advertise female quality in wild baboons. Nature 2001, 410:204-206.

54. Altmann J: Observational study of behavior: sampling methods. Behavior 1974, 49:227-267.

55. Shideler SE, Orturo AM, Moran FM, Moorman EA, Lasley BL: Simple extraction and enzyme immunoassays for estrogen and progesterone metabolites in the feces of Macaca fascicularis during non-conceptive and conceptive ovarian cycles. Biol Reprod 1993, 48:1290-1298.

56. Higham JP, Brent LJN, Dubuc C, Accamando AK, Engelhardt A, Gerald MS, Heistermann M, Stevens M: Color signal information content and the eye of the beholder: a case study in the rhesus macaque. Behav Ecol 2010, 21:739-746.

57. Dubuc C, Brent LJN, Accamando AK, Gerald MS, MacLarnon A, Semple S, Heistermann M, Engelhardt A: Sexual skin color contains information about the timing of the fertile phase in free-ranging rhesus macaques. Int J Primatol 2009, 30:777-789.

58. Hadidian J, Bernstein IS: Female reproductive cycles and birth data from an Old World monkey colony. Primates 1979, 20:429-442.

59. Bates D, Maechler M, Bolker B: Ime4: Linear mixed-effects models using S4 classes.: R package version 0.999375-42; 2011. http://CRAN.R-project.org/ package $=$ Ime4.

60. Hadfield JD: MCMC Methods for Multi-Response Generalized Linear Mixed Models: The MCMCglmm R Package. J Stat Softw 2010, 33:1-22.

61. Weingrill T, Lycett JE, Barrett L, Hill RA, Henzi SP: Male consortship behaviour in chacma baboons: The role of demographic factors and female conceptive probabilities. Behaviour 2003, 140:405-427.

62. Higham JP, Hughes KD, Brent LJN, Dubuc C, Engelhardt A, Heistermann M, Maestripieri D, Santos LR, Stevens M: Familiarity affects assessment of facial signals of female fertility by free-ranging male rhesus macaques. Proc Roy Soc B 2011, 278:3452-3458.

63. Manson JH: Do Female Rhesus Macaques Choose Novel Males? Am J Primatol 1995, 37:285-296.

64. Paul A: Sexual selection and mate choice. Int J Primato/ 2002, 23:877-904

\section{doi:10.1186/1471-2148-12-89}

Cite this article as: Higham et al:: Sexual signalling in female crested macaques and the evolution of primate fertility signals. BMC Evolutionary Biology 2012 12:89.

\section{Submit your next manuscript to BioMed Central and take full advantage of:}

- Convenient online submission

- Thorough peer review

- No space constraints or color figure charges

- Immediate publication on acceptance

- Inclusion in PubMed, CAS, Scopus and Google Scholar

- Research which is freely available for redistribution 